\title{
Association of social network size and composition with physical activity in Korean middle-aged adults
}

\author{
Moon Su Kwak', So Mi Jemma Cho², Jee-Seon Shim ${ }^{2,3,4}$, Dae Jung Kim5, Yoosik Youm', \\ Hyeon Chang Kim ${ }^{2,3,4}$ \\ ${ }^{1}$ Yonsei University College of Medicine, Seoul, Korea; ${ }^{2}$ Department of Preventive Medicine, Yonsei University College of Medicine, Seoul, Korea, \\ ${ }^{3}$ Cardiovascular and Metabolic Diseases Etiology Research Center, Yonsei University College of Medicine, Seoul, Korea; ${ }^{4}$ Integrative Research \\ Center for Cerebrovascular and Cardiovascular Diseases, Yonsei University College of Medicine, Seoul, Korea; ${ }^{5}$ Department of Endocrinology \\ and Metabolism, Ajou University School of Medicine, Suwon, Korea; ${ }^{6}$ Department of Sociology, Yonsei University, Seoul, Korea
}

\begin{abstract}
OBJECTIVES: Physical activity (PA) is an established protective factor for many chronic diseases. Numerous studies have established positive relationships between social networks and PA. Accordingly, this study examined the relationship between social network structures (specifically the network size and the number and proportion of same-sex alters) and self-reported PA in Korean middle-age adults, where the term "alter" refers to a respondent's social network members.

METHODS: We analyzed 8,092 participants of the Cardiovascular and Metabolic Diseases Etiology Research Center cohort. We assessed the association between each network structure variable and PA level using a linear regression model. Then, we employed logistic regression to evaluate associations between social network structure and adherence to guideline-recommended exercise levels. Socio-demographic factors and health status measures were used as covariates.

RESULTS: In both sexes, the social network size and proportion of same-sex network members showed positive relationships with total and moderate-to-vigorous PA. Notably, female participants with a greater number of kin were more likely to satisfy the recommended amount of total $\mathrm{PA}$.
\end{abstract}

CONCLUSIONS: These findings suggest that large scale, same-sex intervention programs can help to achieve recommended $\mathrm{PA}$ regimens.

KEY WORDS: Social network, Lifestyle modification, Physical activity

\section{INTRODUCTION}

Physical activity (PA) is defined as any bodily movement that results in energy expenditure [1]. Many researchers have studied the protective relationship of PA with mental [2,3], cardiovascular

\section{Correspondence: Hyeon Chang Kim}

Department of Preventive Medicine, Yonsei University College of Medicine, 50-1 Yonsei-ro, Seodaemun-gu, Seoul 03722, Korea E-mail:hckim@yuhs.ac

Received: Sep 15, 2020 / Accepted: Nov 24, 2020 / Published: Nov 25, 2020

This article is available from: https://e-epih.org/

(c) This is an open-access article distributed under the terms of the Creative Commons Attribution License (https://creativecommons.org/licenses/by/4.0/), which permits unrestricted use, distribution, and reproduction in any medium, provided the original work is properly cited.

(C) 2020, Korean Society of Epidemiology
[4,5], and metabolic [6] health. As an important lifestyle factor for a wide array of diseases, PA can be promoted by social relationships. Some studies have shown that large network size, frequent contact with network members, and acquaintance with demographically homogeneous network members were associated with higher PA levels [7,8]. Many have speculated that greater exposure to information regarding the benefits of PA and participatory opportunities contribute to such findings. Others have proposed that social interactions boost self-esteem, and thereby increase motivation to care for one's health [7-9]. Specifically, social network promotes PA by providing social support, role modeling, behavioral guidance, and/or required tools/infrastructure [10,11].

As the protective effects of PA have been repeatedly emphasized, it is crucial to reduce physical inactivity at a population level. Previous studies [12,13] have investigated the relationship between social network and PA in Korean elderly and adolescent 
populations; however, no study has focused solely on middleaged population. Hitherto, we examined the association between social network structure and PA level in community-dwelling, middle-aged, Korean adults. Specifically, we explored whether the social network size and composition were associated with total and moderate-to-vigorous physical activity (MVPA).

\section{MATERIALS AND METHODS}

\section{Study participants}

The Cardiovascular and Metabolic Diseases Etiology Research Center (CMERC) cohort consists of two distinct communitydwelling and high-risk clinic populations. In this study, we focused on community-dwelling adults due to the known heterogeneity of social networks in the patient population. Between 2013 and $2018,8,097$ adults (2,808 male, 5,289 female) underwent baseline examination including blood tests and questionnaires on demographics, disease history, health behavior, and psychosocial factors. Detailed descriptions of the CMERC study can be found elsewhere [14]. After excluding 5 participants with extremely high PA levels a total of 8,092 participants were included in the final analysis.

\section{Physical activity assessment}

PA was assessed using the International Physical Activity Questionnaire-Short Form [15]. We obtained combined functional and leisure-time PA, which was described in metabolic equivalent of task (MET) in minutes per week. Based on the previous literature [16], we applied weightings of 3.3, 4.0, and 8.0 METs for light-intensity, moderate-intensity, and vigorous-intensity activities, respectively, to calculate total and MVPA METs. We, then, categorized the participants into MET quartiles accordingly. Examples of light activities included leisurely walking, moderate activities included cycling, and vigorous activities included fastpaced running or strenuous anaerobic training.

\section{Social network structure assessment}

The CMERC cohort study utilized a social network module called name generator, which was originally developed for the General Social Survey in the United States to study social processes with respect to the government system and interpersonal relationships [17]. The Korean version of the name generator has previously been implemented in nationwide social surveys and has been demonstrated to coherently capture important network properties in the context of health studies [18]. In this study, we utilized the name generator module to characterize egocentric social networks.

In detail, participants were asked to list their spouse (if any) and acquaintances (up to 5) with whom they had discussed important matters over the last 12 months. Respondents were referred to as "ego" and their social network members as "alters." Important matters included good or bad experiences, problems, or concerns that the ego had. Next, participants were asked to characterize their relationship with each network member as follows: spouse, parent, child, sibling, neighbor, friend, religious affiliates, health professional, social worker, or others. Parents, children, siblings, and other relatives including in-laws were classified as kin. Then, we inquired on the network members' sex and cohabitation status. Next, participants were asked to rate their emotional closeness to each network member from "not very close" to "extremely close" (coded 1 to 4, respectively). We, then, averaged the scores to obtain a mean closeness score to alters. Participants were also asked to report the conversation frequency with each alter on an 8-point scale, ranging from "less than once per year" to "every day." Scores were assigned according to the approximate number of days per year (e.g., "every day" = 365; "once a month" = 12) and were summed across all alters to obtain a measure of overall volume of contact.

From the module, we synthesized measures of social network size $(0-1,2,3, \geq 4)$ and the number $(0,1,2,3, \geq 4)$ and proportion $(0-25,25-50,50-75,75-100 \%)$ of same-sex alters and kin. The difference between people with 0 network size and those with 1 network size 1 , and the results of the analysis separating 0 and 1 are presented in Supplementary Materials 1-3.

\section{Covariates}

We collected demographics, disease history, and health behaviors from face-to-face interviews using structured questionnaires. Participants were classified as current, former, or non-drinkers. Obesity was defined based on the 2018 Korean Society for the Study of Obesity guideline [19] as a body mass index $\geq 25.0 \mathrm{~kg} / \mathrm{m}^{2}$. Hypertension was defined based on the 2018 Korean Society of Hypertension guideline [20] for high blood pressure as a systolic blood pressure $\geq 140 \mathrm{mmHg}$, diastolic blood pressure $\geq 90 \mathrm{mmHg}$, or taking antihypertensive medications. Diabetes mellitus was defined based on the 2019 Korean Diabetes Association guideline [21] as an eight-hour fasting glucose of $\geq 126 \mathrm{mg} / \mathrm{dL}$, hemoglobin A1c level $\geq 6.5 \%$, taking glucose-lowering agent, or receiving insulin injections. Hypercholesterolemia and hypertriglyceridemia were defined based on the 2018 Korean Society of Lipid and Atherosclerosis guideline [22] as a total cholesterol $\geq 240 \mathrm{mg} / \mathrm{dL}$, a triglyceride level $\geq 200 \mathrm{mg} / \mathrm{dL}$, or taking lipid-lowering drugs. All bioassays were performed at a single designated research laboratory (Seoul Clinical Laboratory R\&D Center, Seoul, Korea).

\section{Statistical analysis}

We compared the baseline characteristics by sex using independent t-test. Next, we evaluated the linear associations between network structure variables and PA level, adjusting for age, body mass index, marital status, cohabitation status, education level, household income, occupation, smoking, and alcohol drinking. Furthermore, we assessed categorical association between social network structure and adherence to guideline-recommended [23] exercise engagement by multivariable logistic regression. Participants who achieved $500 \mathrm{MET}-\mathrm{min} / \mathrm{wk}$ of total PA or $150 \mathrm{~min} / \mathrm{wk}$ of MVPA were classified as guideline-adherent. 
All statistical tests were 2-sided, and statistical significance was set at a $\mathrm{p}$-value $<0.05$. All analyses were performed using SAS version 9.4 (SAS Institute Inc., Cary, NC, USA).

\section{Ethics statement}

The CMERC cohort study was approved by the institutional review boards of Severance Hospital, Yonsei University Health System, Seoul, Korea (4-2013-0661) and Ajou University School of Medicine, Suwon, Korea (AJIRB-BMR-SUR-13-272).

We obtained written informed consent from all participants prior to the baseline examination.

\section{RESULTS}

Table 1 presents the general characteristics of study participants by sex. On average, females were older than males (51.8 vs. 50.7 years). Although males were more likely to be more obese ( 48.2 vs. $18.0 \%$ ), they also performed more PA than females (2,425.0 vs. 1846.8 total MET-min/wk; 243.5 vs. 150.8 MVPA MET-min/wk).

Table 2 shows linear association between social network structure and PA level. In both sexes, the network size was positively associated with both total (male: $\beta=367.2, p<0.001$; female: $\beta=$ 271.3, $\mathrm{p}<0.001$ ) and MVPA (male: $\beta=30.2, \mathrm{p}<0.001$; female: $\beta=20.5, p<0.001)$ METs. The number of same-sex alters also showed positive relationships with both total (male: $\beta=311.2$, $\mathrm{p}<0.001$; female: $\beta=230.6, \mathrm{p}<0.001$ ) and MVPA (male: $\beta=26.6$, $\mathrm{p}<0.001$; female: $\beta=17.3, \mathrm{p}<0.001)$ METs. The associations remained robust for the proportion of same-sex alters. Next, the number of kin showed positive relationship with total PA (male: $\beta=206.8, p=0.002$; female: $\beta=92.7, p=0.004$ ) and MVPA (male: $\beta=24.0, p=0.011$; female: $\beta=10.4, p=0.014$ ) in both sexes. However, in males, the proportion of kin showed a negative relationship with total PA $(\beta=-155.2, p=0.004)$ yet no significant relationship with MVPA $(\beta=-6.1, \mathrm{p}=0.428)$. No significant associations were observed with the proportion of kin in female.

Table 3 shows the associations between social network structure and adherence to the guideline-recommended exercise levels. Male participants with a larger network size and a higher number and proportion of same-sex alters were more likely to engage in the recommended amount of PA. However, no meaningful associations were observed based on the number or proportion of kin within their networks. Likewise, female participants with a larger network size and a higher proportion of samesex alters were more likely to achieve the recommended amount of PA. Furthermore, those with greater number of kin within the network were also likely to engage in the recommended amount of total PA, but not MVPA.

\section{DISCUSSION}

In this study, we found sex-specific associations of social network size and the proportion of same-sex alters and kin with PA levels. Unlike male, female with a greater number of kin were
Table 1. General characteristics of the study population $(n=8,092)$

\begin{tabular}{|c|c|c|c|}
\hline Variables & $\begin{array}{c}\text { Male } \\
(n=2,805)\end{array}$ & $\begin{array}{l}\text { Female } \\
(n=5,287)\end{array}$ & $p$-value ${ }^{1}$ \\
\hline Age (yr) & $50.74 \pm 9.34$ & $51.78 \pm 8.32$ & $<0.001$ \\
\hline \multicolumn{4}{|l|}{ Marital status } \\
\hline Married and cohabiting & $2,596(92.5)$ & $4,457(84.3)$ & $<0.001$ \\
\hline $\begin{array}{l}\text { Married yet not } \\
\text { cohabiting }\end{array}$ & $13(0.5)$ & $63(1.2)$ & \\
\hline Widowed & $8(0.3)$ & $300(5.7)$ & \\
\hline Divorced & $43(1.5)$ & $287(5.4)$ & \\
\hline Unmarried & $145(5.2)$ & $180(3.4)$ & \\
\hline \multicolumn{4}{|l|}{ Cohabitation } \\
\hline $\begin{array}{l}\text { With partner or family } \\
\text { member }\end{array}$ & $2,720(97.0)$ & $5,014(94.8)$ & $<0.001$ \\
\hline With non-family member & $14(0.5)$ & $20(0.4)$ & \\
\hline Single & $71(2.5)$ & $253(4.8)$ & \\
\hline \multicolumn{4}{|l|}{ Education level } \\
\hline $\begin{array}{l}\text { Elementary school or } \\
\text { below }\end{array}$ & $78(2.8)$ & $339(6.4)$ & $<0.001$ \\
\hline Middle school & $160(5.7)$ & $620(11.7)$ & \\
\hline High school & $994(35.4)$ & $2,506(47.4)$ & \\
\hline $\begin{array}{l}\text { College/university or } \\
\text { above }\end{array}$ & $1,573(56.1)$ & $1,821(34.4)$ & \\
\hline \multicolumn{4}{|l|}{ Household income } \\
\hline Low & $538(19.2)$ & $1,369(25.9)$ & $<0.001$ \\
\hline Middle-low & $680(24.2)$ & $1,311(24.8)$ & \\
\hline Middle-high & $758(27.0)$ & $1,311(24.8)$ & \\
\hline High & $829(29.5)$ & $1,296(24.5)$ & \\
\hline \multicolumn{4}{|l|}{ Occupation } \\
\hline White-collar & $1,469(52.4)$ & $1,307(24.7)$ & $<0.001$ \\
\hline Blue-collar & $1,082(38.6)$ & $1,599(30.2)$ & \\
\hline Unemployed & $254(9.1)$ & $2,381(45.0)$ & \\
\hline \multicolumn{4}{|l|}{ Cigarette smoking } \\
\hline Non-smoker & $627(22.3)$ & $4,973(94.1)$ & $<0.001$ \\
\hline Former smoker & $1,257(44.8)$ & $177(3.3)$ & \\
\hline Current smoker & $921(32.8)$ & $137(2.6)$ & \\
\hline \multicolumn{4}{|l|}{ Alcohol consumption } \\
\hline Non-drinkers & $272(9.7)$ & $1,769(33.5)$ & $<0.001$ \\
\hline Former drinkers & $158(5.6)$ & $144(2.7)$ & \\
\hline Current drinkers & $2,375(84.7)$ & $3,374(63.8)$ & \\
\hline \multicolumn{4}{|l|}{ Physical activity } \\
\hline Total MET (MET min/wk) & $2,425.0 \pm 3,371.4$ & $1,846.8 \pm 2,594.2$ & \\
\hline MVPA (MET min/wk) & $243.5 \pm 483.8$ & $150.8 \pm 343.3$ & $<0.000$ \\
\hline Sedentary time (min/wk) & $407.9 \pm 208.8$ & $341.8 \pm 180.4$ & $<0.001$ \\
\hline \multicolumn{4}{|l|}{ Morbidities } \\
\hline Obese & $1,353(48.2)$ & $1,456(27.5)$ & $<0.001$ \\
\hline Hypertension & $624(22.2)$ & $813(15.4)$ & $<0.001$ \\
\hline Diabetes mellitus & $383(13.6)$ & $403(7.6)$ & $<0.001$ \\
\hline Dyslipidemia & $384(13.7)$ & $904(17.1)$ & $<0.001$ \\
\hline
\end{tabular}

Values are presented as mean \pm standard deviation or number (\%). MET, metabolic equivalent of task; MVPA, moderate-to-vigorous physical activity.

${ }^{1}$ From the independent t-test. 
Table 2. Associations between social network structure and physical activity level $(n=8,092)$

\begin{tabular}{|c|c|c|c|c|c|c|c|c|}
\hline \multirow{3}{*}{ Characteristics } & \multicolumn{4}{|c|}{ Total METs } & \multicolumn{4}{|c|}{ MVPA } \\
\hline & \multicolumn{2}{|c|}{ Unadjusted } & \multicolumn{2}{|c|}{ Adjusted ${ }^{1}$} & \multicolumn{2}{|c|}{ Unadjusted } & \multicolumn{2}{|c|}{ Adjusted $^{1}$} \\
\hline & $\beta$ & $\mathrm{p}$-value & $\beta$ & $\mathrm{p}$-value & $\beta$ & $p$-value & $\beta$ & $\mathrm{p}$-value \\
\hline \multicolumn{9}{|l|}{ Male $(n=2,805)$} \\
\hline Network size & 315.2 & $<0.001$ & 367.2 & $<0.001$ & 24.1 & 0.001 & 30.2 & $<0.001$ \\
\hline No. of same-sex alters & 272.6 & $<0.001$ & 311.2 & $<0.001$ & 22.6 & 0.000 & 26.6 & $<0.001$ \\
\hline Proportion of same-sex alters & 314.1 & $<0.001$ & 360.0 & $<0.001$ & 27.9 & 0.001 & 31.5 & $<0.001$ \\
\hline No. of kin & 173.3 & 0.008 & 206.8 & 0.002 & 17.7 & 0.058 & 24.0 & 0.011 \\
\hline Proportion of kin & -142.7 & 0.007 & -155.2 & 0.004 & -6.5 & 0.396 & -6.1 & 0.428 \\
\hline \multicolumn{9}{|l|}{ Female $(n=5,287)$} \\
\hline Network size & 236.1 & $<0.001$ & 271.3 & $<0.001$ & 18.1 & $<0.001$ & 20.5 & $<0.001$ \\
\hline No. of same-sex alters & 209.7 & $<0.001$ & 230.6 & $<0.001$ & 15.5 & $<0.001$ & 17.3 & $<0.001$ \\
\hline Proportion of same-sex alters & 245.3 & $<0.001$ & 274.8 & $<0.001$ & 16.1 & 0.001 & 19.2 & $<0.001$ \\
\hline No. of kin & 69.4 & 0.027 & 92.7 & 0.004 & 9.3 & 0.025 & 10.4 & 0.014 \\
\hline Proportion of kin & -68.2 & 0.029 & -71.2 & 0.024 & -1.0 & 0.810 & -1.9 & 0.649 \\
\hline
\end{tabular}

MET, metabolic equivalent of task; MVPA, moderate-to-vigorous physical activity.

'Adjusted for age, body mass index, marital status, cohabitation status, education level, household income, occupation, smoking, alcohol drinking, and obesity.

more likely to satisfy the recommended amount of PA in terms of total PA. In both sexes, all social network composition variables, except for the proportion of kin, showed positive relationships with PA of all rigors.

Our findings support and complement previously reported associations between social networks and PA. The 1990 Ontario Health Survey showed positive associations between social quantity (number of close relatives and friends) and self-reported PA [24]. In another study [25] based on residents of 12 low-income housing communities in metropolitan Boston, residents with smaller social networks were significantly less physically active based on pedometer measurements than their counterparts with larger social networks. One proposed mechanism is that a large network size enables individuals to receive more information on the benefits of PA and opportunities to participate [8]. Others speculate that a larger network can elevate one's self esteem by positive interactions within the network, thereby increasing motivation to attend to one's health [7].

In addition, our results indicate that the number and proportion of same-sex members within one's social network were positively associated with PA level in both sexes. In a study based on 6 Catholic schools in Calgary [26], social density and friendship intimacy were positively associated with meeting the recommended amount of MVPA (self-reported). The authors observed that for male, the presence of physically active friends within the network encouraged ego to engage in more PA, while in female, emotional support from female friends inspired greater PA [26]. In a Brazilian occupational study [27], material support was positively associated with PA in female (odds ratio, 2.76). Affective support was associated with time spent on leisure-time PA only in male (odds ratio, 1.80) [27].

Whereas the number of kin showed a positive association with PA levels in female, contrasting results were observed in male.
Previous studies suggested that a lack of confidence on initiating PA, lack of network members who are familiar and competent with PA, negative self-perceptions regarding body image, and insufficient time for PA due to caregiving responsibilities are potential barriers to PA engagement in middle-aged male [28]. Therefore, the disproportionate family-caretaking role in Korean households [29-31] may explain the negative relationship between PA level and number of kin observed in our male participants.

Regarding the positive association between PA level and number of kin in female, family members' motivation may encourage female to engage in PA. Indeed, previous studies [32-34] have shown that female tend to participate in PA with their family members, whereas male prefer to do so independently or with non-family members. This may furnish a natural explanation of higher PA in female participants with a greater number of kin.

This study has several strengths. To our knowledge, few studies have examined the associations between social network structure and PA in middle-aged Korean adults. Considering that lifetime exposure to PA is crucial in the context of primary and secondary prevention of chronic diseases, our study may provide evidence for more holistic and persistent intervention programs. Second, this study included a large number of participants, thereby yielding statistically robust results. Third, we investigated various aspects of the social network composition, which enabled us to specify characteristics of the network structure associated with PA.

However, there are some limitations to be considered. First, as the study design was cross-sectional, we were unable to draw conclusions regarding the causality of associations between social network structure and PA. Second, we relied on a subjective measure of PA, which can yield differential misclassification bias. Lastly, the associations between social network structure and MVPA were inconsistent. Future studies based on objective measures of MVPA that can effectively distinguish between functional 
Table 3. Associations between social network structure and adherence to guideline-recommended PA in sexes

\begin{tabular}{|c|c|c|c|c|c|c|c|}
\hline \multirow[b]{2}{*}{ Social network structure } & \multirow[b]{2}{*}{$\begin{array}{c}\text { No. of } \\
\text { participants }\end{array}$} & \multicolumn{3}{|c|}{ Total METs } & \multicolumn{3}{|c|}{ MVPA } \\
\hline & & $\begin{array}{l}\text { Meeting the } \\
\text { recommended } \\
\text { PA level, n (\%) }\end{array}$ & $\begin{array}{l}\text { Unadjusted OR } \\
\qquad(95 \% \mathrm{Cl})\end{array}$ & $\begin{array}{l}\text { Adjusted OR } \\
(95 \% \mathrm{Cl})^{1}\end{array}$ & $\begin{array}{l}\text { Meeting the } \\
\text { recommended } \\
\text { PA level, } \mathrm{n}(\%)\end{array}$ & $\begin{array}{l}\text { Unadjusted OR } \\
\qquad(95 \% \mathrm{Cl})\end{array}$ & $\begin{array}{l}\text { Adjusted OR } \\
\qquad(95 \% \mathrm{Cl})^{1}\end{array}$ \\
\hline
\end{tabular}

Male $(n=2,805)$

Network size

$\begin{array}{lrrrr}0-1 & 665 & 427(64.2) & 1.00 \text { (reference) } & 1.00 \text { (reference) } \\ 2 & 407 & 287(70.5) & 1.33(1.02,1.74) & 1.41(1.08,1.85) \\ 3 & 601 & 440(73.2) & 1.52(1.20,1.94) & 1.61(1.26,2.06) \\ \geq 4 & 1,132 & 917(81.0) & 2.38(1.91,2.95) & 2.60(2.07,3.26) \\ \text { No. of same-sex alters } & & & & \\ 0 & 723 & 467(64.6) & 1.00 \text { (reference) } & 1.00 \text { (reference) } \\ 1 & 523 & 374(71.5) & 1.38(1.08,1.76) & 1.41(1.10,1.81) \\ 2 & 603 & 459(76.1) & 1.75(1.37,2.22) & 1.83(1.43,2.34) \\ 3 & 370 & 287(77.6) & 1.90(1.42,2.53) & 2.04(1.52,2.74) \\ \geq 4 & 586 & 484(82.6) & 2.60(2.00,3.38) & 2.77(2.12,3.63) \\ \text { Percent of same-sex alters } & & & & \\ 0-25 & 765 & 499(65.2) & 1.00(\text { reference) } & 1.00(\text { reference }) \\ 25-50 & 665 & 499(75.0) & 1.60(1.27,2.02) & 1.65(1.30,2.09) \\ 50-75 & 863 & 652(75.6) & 1.65(1.33,2.04) & 1.74(1.39,2.17) \\ 75-100 & 512 & 421(82.2) & 2.47(1.88,3.23) & 2.54(1.92,3.36) \\ \text { No. of kin } & & & & \\ 0 & 503 & 360(71.5) & 1.00 \text { (reference) } & 1.00(\text { reference) } \\ 1 & 1,604 & 1154(72.0) & 1.02(0.82,1.27) & 1.08(0.85,1.36) \\ 2 & 360 & 291(80.8) & 1.68(1.21,2.32) & 1.80(1.29,2.51) \\ 3 & 212 & 163(76.9) & 1.32(0.91,1.92) & 1.41(0.96,2.06) \\ \geq 4 & 126 & 103(81.75) & 1.78(1.09,2.91) & 2.04(1,23,3.37) \\ \text { Percent of kin } & & & & \\ 0 & & & & \end{array}$

Percent of kin

$\begin{array}{lr}0-25 & 1,01 \\ 25-50 & 85 \\ 50-75 & 19 \\ 75-100 & 74\end{array}$

Female $(n=5,287)$

Network size

0-1

2

3

$\geq 4$

No. of same-sex alters

1

2

3

$\geq 4$

Percent of same-sex alters

$0-25$

25-50

50-75

75-100

No. of kin

0

$1 \quad 2,129$

$2 \quad 1,251$

$3 \quad 736$

$\geq 4 \quad 454$

Percent of kin

$0-25$

25-50

50-75

75-100
, 016

855

743

628

850

1,319

2,490

645

909

1,349

953

1,431

679

1,053

1,988

1,567

717

251
736

1,442

1,697

766

1,382
$772(76.0)$

$644(75.3)$

156 (81.7)

499 (67.2)

373 (59.4)

526 (61.9)

896 (67.9)

1,803 (72.4)

389 (60.3)

549 (60.4)

931 (69.0)

665 (69.8)

1,064 (74.4)

409 (60.2)

667 (63.3)

$1,380(69.4)$

1,142 (72.9)

461 (64.3)

$1447(68.0)$

$852(68.1)$

511 (69.4)

$327(72.0)$

988 (68.5)

$536(70.0)$

892 (64.5)
$1,182(69.65)$
1.00 (reference) 1.00 (reference) $0.97(0.78,1.19) \quad 1.00(0.80,1.23)$

$1.41(0.95,2.09) \quad 1.40(0.94,2.10)$ $0.65(0.52,0.80) \quad 0.64(0.52,0.80)$

1.00 (reference) 1.00 (reference)

$1.11(0.90,1.37) \quad 1.12(0.90,1.38)$

$1.79(1.50,2.15) \quad 1.94(1.61,2.34)$

1.00 (reference) 1.00 (reference)

$1.00(0.82,1.23) \quad 1.02(0.83,1.26)$

$1.47(1.21,1.78) \quad 1.54(1.26,1.88)$

$1.52(1.23,1.87) \quad 1.62(1.31,2.00)$

$1.91(1.57,2.32) \quad 2.05(1.68,2.51)$

1.00 (reference) 1.00 (reference)

$1.14(0.94,1.39) \quad 1.16(0.95,1.42)$

$1.50(1.25,1.80) \quad 1.56(1.30,1.88)$

$1.77(1.47,2.15) \quad 1.94(1.59,2.36)$

1.00 (reference) 1.00 (reference)

$1.18(0.99,1.41) \quad 1.25(1.03,1.51)$

$1.19(0.98,1.44) \quad 1.27(1.03,1.55)$

$1.26(1.01,1.57) \quad 1.36(1.08,1.70)$

$1.43(1.11,1.85) \quad 1.53(1.17,2.00)$

1.00 (reference) 1.00 (reference)

$1.06(0.91,1.23) \quad 1.07(0.91,1.25)$

$1.07(0.89,1.30) \quad 1.08(0.89,1.31)$

$0.84(0.72,0.98) \quad 0.82(0.69,0.96)$
$1.45(1.19,1.76) \quad 1.52(1.24,1.86)$

231 (34.7) 1.00 (reference) 1.00 (reference)

$150(36.9) \quad 1.10(0.85,1.42) \quad 1.14(0.88,1.48)$

$218(36.3) \quad 1.07(0.85,1.35) \quad 1.12(0.88,1.41)$

$517(45.7) \quad 1.58(1.30,1.93) \quad 1.66(1.36,2.04)$

250 (34.6) 1.00 (reference) 1.00 (reference) $188(36.0) \quad 1.06(0.84,1.34) \quad 1.09(0.86,1.38)$ $238(39.5) \quad 1.23(0.99,1.54) \quad 1.28(1.02,1.61)$ $168(45.4) \quad 1.57(1.22,2.03) \quad 1.64(1.26,2.13)$

$272(46.4) \quad 1.64(1.31,2.05) \quad 1.70(1.35,2.14)$

270 (35.3) 1.00 (reference) 1.00 (reference) $254(38.2) \quad 1.13(0.91,1.41) \quad 1.16(0.93,1.45)$ $354(41.0) \quad 1.28(1.04,1.56) \quad 1.31(1.07,1.61)$

$238(46.5) \quad 1.60(1.27,2.00) \quad 1.63(1.29,2.06)$

188 (37.4) 1.00 (reference) 1.00 (reference) $625(22.3) \quad 1.07(0.87,1.32) \quad 1.11(0.89,1.38)$ $155(43.1) \quad 1.27(0.96,1.67) \quad 1.32(1.00,1.75)$ $88(41.5) \quad 1.19(0.86,1.65) \quad 1.25(0.90,1.75)$ $60(47.6) \quad 1.52(1.03,2.26) \quad 1.64(1.10,2.46)$

425 (41.8) 1.00 (reference) 1.00 (reference) $330(38.6) \quad 0.87(0.73,1.05) \quad 0.89(0.74,1.08)$ $77(40.3) \quad 0.94(0.69,1.29) \quad 0.94(0.68,1.29)$ $284(38.2) \quad 0.86(0.71,1.04) \quad 0.87(0.71,1.05)$

167 (26.6) 1.00 (reference) 1.00 (reference) $219(25.8) \quad 0.96(0.76,1.21) \quad 0.96(0.76,1.21)$ $363(27.5) \quad 1.05(0.85,1.30) \quad 1.05(0.85,1.30)$ $806(32.4) \quad 1.32(1.09,1.61) \quad 1.32(1.09,1.61)$

177 (27.4) 1.00 (reference) 1.00 (reference) $225(24.8) \quad 0.87(0.69,1.09) \quad 0.87(0.69,1.10)$ $392(29.1) \quad 1.08(0.88,1.34) \quad 1.11(0.89,1.37)$ $268(28.1) \quad 1.03(0.83,1.29) \quad 1.07(0.85,1.34)$ $493(34.5) \quad 1.39(1.13,1.71) \quad 1.45(1.18,1.78)$

182 (26.8) 1.00 (reference) 1.00 (reference) $284(27.0) \quad 1.01(0.81,1.25) \quad 1.00(0.80,1.25)$ $578(29.1) \quad 1.12(0.92,1.36) \quad 1.12(0.91,1.36)$ $511(32.6) \quad 1.32(1.08,1.61) \quad 1.45(1.18,1.78)$

186 (25.9) 1.00 (reference) 1.00 (reference) $660(31.0) \quad 1.28(1.06,1.55) \quad 1.26(1.03,1.54)$ $353(28.2) \quad 1.12(0.91,1.38) \quad 1.10(0.88,1.37)$ $214(29.1) \quad 1.17(0.93,1.47) \quad 1.17(0.92,1.48)$ $142(31.3) \quad 1.30(1.00,1.68) \quad 1.27(0.97,1.66)$

438 (30.4) 1.00 (reference) 1.00 (reference) $506(29.8) \quad 0.97(0.84,1.13) \quad 0.95(0.81,1.11)$ $227(29.6) \quad 0.97(0.80,1.17) \quad 0.93(0.77,1.13)$ $384(27.8) \quad 0.88(0.75,1.04) \quad 0.84(0.71,0.99)$

PA, physical activity; MET, metabolic equivalent of task; MVPA, moderate-to-vigorous physical activity; OR, odds ratio; Cl, confidence interval. ${ }^{1}$ Adjusted for age, body mass index, marital status, cohabitation status, education level, household income, occupation, smoking, alcohol drinking, and obesity. 
and leisure-time PAs may further strengthen the findings.

In conclusion, we observed sex-specific associations of social network size and network composition (the proportion of samesex alters) with PA. Beyond individual-level characteristics, a consideration of interpersonal aspects may be helpful to achieve optimal PA.

\section{SUPPLEMENTARY MATERIALS}

Supplementary materials are available at http://www.e-epih. org/.

\section{CONFLICT OF INTEREST}

The authors have no conflicts of interest to declare for this study.

\section{FUNDING}

This research was supported by the Basic Research Program through the National Research Foundation of Korea (NRF) funded by the MSIT (grant number: 2019R1A4A1028155).

\section{ACKNOWLEDGEMENTS}

None.

\section{AUTHOR CONTRIBUTIONS}

Conceptualization: MSK, SMJC, HCK. Data curation: JSS, DJK, HCK. Formal analysis: MSK, SMJC. Funding acquisition: DJK, HCK. Methodology: SMJC, JSS, HCK. Project administration: JSS, HCK. Visualization: MSK. Writing - original draft: MSK. Writing - review \& editing: SMJC, JSS, DJK, YY, HCK.

\section{ORCID}

Moon Su Kwak: http://orcid.org/0000-0002-0957-3281; So Mi Jemma Cho: $h t t p: / / o r c i d . o r g / 0000-0003-2460-3335$; Jee-Seon Shim: http://orcid.org/0000-0002-8671-3153; Dae Jung Kim: http://orcid. org/0000-0003-1025-2044; Yoosik Youm: http://orcid.org/00000003-3822-5777; Hyeon Chang Kim: http://orcid.org/0000-0001$7867-1240$

\section{REFERENCES}

1. Caspersen CJ, Powell KE, Christenson GM. Physical activity, exercise, and physical fitness: definitions and distinctions for healthrelated research. Public Health Rep 1985;100:126-131.

2. Schuch FB, Vancampfort D, Richards J, Rosenbaum S, Ward PB, Stubbs B. Exercise as a treatment for depression: a meta-analysis adjusting for publication bias. J Psychiatr Res 2016;77:42-51.

3. Firth J, Stubbs B, Rosenbaum S, Vancampfort D, Malchow B,
Schuch F, et al. Aerobic exercise improves cognitive functioning in people with schizophrenia: a systematic review and meta-analysis. Schizophr Bull 2017;43:546-556.

4. Delaney JA, Jensky NE, Criqui MH, Whitt-Glover MC, Lima JA, Allison MA. The association between physical activity and both incident coronary artery calcification and ankle brachial index progression: the multi-ethnic study of atherosclerosis. Atherosclerosis 2013;230:278-283.

5. Halle M, Berg A, König D, Keul J, Baumstark MW. Differences in the concentration and composition of low-density lipoprotein subfraction particles between sedentary and trained hypercholesterolemic men. Metabolism 1997;46:186-191.

6. Kim J, Tanabe K, Yokoyama N, Zempo H, Kuno S. Association between physical activity and metabolic syndrome in middle-aged Japanese: a cross-sectional study. BMC Public Health 2011;11:624.

7. Cohen S. Psychosocial models of the role of social support in the etiology of physical disease. Health Psychol 1988;7:269-297.

8. Gottlieb B. The meaning and importance of social support. In: Quinney H, Gauvin L, Wall E, editors. Toward active living: proceedings of the International Conference on Physical Activity, Fitness, and Health. Champaign: Human Kinetics; 1994, p. 227232.

9. Ståhl T, Rütten A, Nutbeam D, Bauman A, Kannas L, Abel T, et al. The importance of the social environment for physically active lifestyle--results from an international study. Soc Sci Med 2001; 52:1-10.

10. McNeill LH, Kreuter MW, Subramanian SV. Social environment and physical activity: a review of concepts and evidence. Soc Sci Med 2006;63:1011-1022.

11. Berkman LF, Glass T, Brissette I, Seeman TE. From social integration to health: Durkheim in the new millennium. Soc Sci Med 2000;51:843-857.

12. Park DH, Kim JY, Park JY, Choi SI, Kim WJ, Kim YC, et al. Association among social network size, physical activity and self-rated health in Korean elderly: the Korea Urban Rural Elderly cohort study (KURE) 2012-2015. Korean J Sport Stud 2018;57:149-160 (Korean).

13. Kim YH, Cardinal BJ. Psychosocial correlates of Korean adolescents' physical activity behavior. J Exerc Sci Fit 2010;8:97-104.

14. Shim JS, Song BM, Lee JH, Lee SW, Park JH, Choi DP, et al. Cohort profile: the Cardiovascular and Metabolic Diseases Etiology Research Center Cohort in Korea. Yonsei Med J 2019;60:804-810.

15. Chun MY. Validity and reliability of Korean version of international physical activity questionnaire short form in the elderly. Korean J Fam Med 2012;33:144-151.

16. Burt RS. Network items and the general social survey. Soc Netw 1984;6:293-339.

17. Youm Y, Laumann EO, Ferraro KF, Waite LJ, Kim HC, Park YR, et al. Social network properties and self-rated health in later life: comparisons from the Korean social life, health, and aging project and the national social life, health and aging project. BMC Geriatr 2014;14:102.

18. Cornwell B, Schumm LP, Laumann EO, Graber J. Social networks 
in the NSHAP Study: rationale, measurement, and preliminary findings. J Gerontol B Psychol Sci Soc Sci 2009;64 Suppl 1(Suppl 1):i47-i55.

19. Korean Society for the Study of Obesity. Guideline for the management of obesity 2018. Seoul: Korean Society for the Study of Obesity; 2018, p. 21-27 (Korean).

20. Korean Society of Hypertension. Guideline for hypertenion 2018. Seoul: Korean Society of Hypertension; 2018, p. 14 (Korean).

21. Korean Diabetes Association. Treatment guideline for diabetes. 6th ed. Seoul: Korean Diabetes Association; 2019, p. 13-17 (Korean).

22. Korean Society of Lipid and Atherosclerosis. Korean guidelines for the management of dyslipidemia 4th ed. Seoul: 2018, p. 31-33 (Korean).

23. U.S. Department of Health and Human Services. 2008 Physical activity guidelines for Americans [cited 2020 Sep 1]. Available from: https://health.gov/sites/default/files/2019-09/paguide.pdf.

24. Spanier PA, Allison KR. General social support and physical activity: an analysis of the Ontario Health Survey. Can J Public Health 2001;92:210-213.

25. Shelton RC, McNeill LH, Puleo E, Wolin KY, Emmons KM, Bennett GG. The association between social factors and physical activity among low-income adults living in public housing. Am J Public Health 2011;101:2102-2110.

26. Sawka KJ, McCormack GR, Nettel-Aguirre A, Blackstaffe A, Perry R, Hawe P. Associations between aspects of friendship networks, physical activity, and sedentary behaviour among adolescents. J Obes 2014;2014:632689.

27. Oliveira AJ, Lopes CS, Rostila M, Werneck GL, Griep RH, Leon
AC, et al. Gender differences in social support and leisure-time physical activity. Rev Saude Publica 2014;48:602-612.

28. Allender S, Cowburn G, Foster C. Understanding participation in sport and physical activity among children and adults: a review of qualitative studies. Health Educ Res 2006;21:826-835.

29. Choe MK. Modernization, gender roles, and marriage behavior in South Korea. In: Lee SH, Chang YS, editors. Transformations in twentieth century Korea. New York: Routledge, 2006, p. 291309.

30. Porch TC, Bell CN, Bowie JV, Usher T, Kelly EA, LaVeist TA, et al. The role of marital status in physical activity among African American and white men. Am J Mens Health 2016;10:526-532.

31. Caperchione CM, Vandelanotte C, Kolt GS, Duncan M, Ellison $\mathrm{M}$, George E, et al. What a man wants: understanding the challenges and motivations to physical activity participation and healthy eating in middle-aged Australian men. Am J Mens Health 2012; 6:453-461.

32. Lenhart CM, Hanlon A, Kang Y, Daly BP, Brown MD, Patterson F. Gender disparity in structured physical activity and overall activity level in adolescence: evaluation of youth risk behavior surveillance data. ISRN Public Health 2012;2012:674936.

33. van Uffelen JG, Khan A, Burton NW. Gender differences in physical activity motivators and context preferences: a population-based study in people in their sixties. BMC Public Health 2017;17:624.

34. El Ansari W, Khalil K, Crone D, Stock C. Physical activity and gender differences: correlates of compliance with recommended levels of five forms of physical activity among students at nine universities in Libya. Cent Eur J Public Health 2014;22:98-105. 